\title{
Obesity Prevalence in the Long-Term Future in 18 European Countries and in the USA
}

\author{
Fanny Janssen ${ }^{a, b} \quad$ Anastasios Bardoutsos ${ }^{a} \quad$ Nikoletta Vidra ${ }^{a, c}$ \\ a Population Research Centre, Faculty of Spatial Sciences, University of Groningen, \\ Groningen, The Netherlands; ${ }^{b}$ Netherlands Interdisciplinary Demographic Institute, KNAW/ \\ University of Groningen, The Hague, The Netherlands; ' Department for Health Evidence, \\ Radboud Institute for Health Sciences, Radboud University Medical Center, Nijmegen, \\ The Netherlands
}

\section{Keywords}

Obesity $\cdot$ Europe $\cdot$ Future $\cdot$ Modelling $\cdot$ Projecting

\begin{abstract}
Introduction: Obesity constitutes a major public health problem in Europe, but how the obesity epidemic in European countries will evolve remains unknown. Most previous obesity projections considered the short-term future only, focused on single non-European countries, and projected ongoing increases foremost. We comparatively project obesity prevalence into the long-term future for 18 European countries and the USA. Data: We used national agespecific (20-84 years) and sex-specific obesity prevalence estimates (1975-2016) from the NCD Risk Factor Collaboration (NCD-RisC) 2017 study, which are based on available measured height and weight data, supplemented with estimates from a Bayesian hierarchical model. Methods: We projected age- and sex-specific obesity prevalence up to the year 2100 by integrating the notion of a wave-shaped obesity epidemic into conventional age-period projections. Results: In 1990-2016, the increasing trends in obesity prevalence were decelerating. Obesity is expected to reach maximum levels between 2030 and 2052 among men, and between 2026 and 2054 among women. The maximum levels will likely be reached first in The Netherlands, USA, and UK, and last in Switzerland; and are expected to be highest in the USA and UK, and lowest in The Netherlands for men and Denmark for women. In 2060, obesity prevalence is expected to be lowest among Dutch men and highest among Swiss men. The projected age-specific obesity prevalence levels have an inverse U-shape, peaking at around the age of 60-69 years. Discussion: Applying our novel approach to the NCD-RisC 2017 data, obesity prevalence is expected to reach maximum levels between 2026 and 2054, with the USA and UK reaching the highest maximum levels first, followed by other European countries.
\end{abstract}




\section{Introduction}

Obesity has increased dramatically over the last 4 decades [1,2]. While the USA currently ranks first in obesity prevalence levels (36.5\% in 2011-2014) [3], Europe is in second place globally, with an average prevalence of $15.9 \%$ across EU member states in 2014 [4]. As obesity is recognized as a major public health problem in Europe [2,5], research to shed a light on its likely future evolution in European countries is warranted.

Comparative long-term projections of obesity prevalence in Europe are, however, lacking. With one exception, previous projections of adult obesity prevalence at the national level in Europe and the USA have provided only short-term estimates, i.e., up to 2030 [6-14]. Moreover, most of the previous projection studies of adult mortality focused on only one nonEuropean country; usually the USA [6,9-14]. The 3 studies that included $>1$ European country provided forecasts that extended no more than 16 years into the future $[7,8,12]$. In addition, the methodologies employed in these previous projections differed substantially, and not all were able to produce realistic obesity estimates for the long-term future. For example, some of the studies applied linear extrapolations that assumed that the strong past increase in obesity would continue $[6,14]$, which, when applied to the long-term future, would generate obesity levels close to $100 \%$. Such a linear extrapolation of past increasing obesity prevalence trends was also applied in a projection of the global obesity prevalence up to 2030 [15], and as part of a recent forecast of life expectancy and all-cause mortality up to 2040 for 195 countries and territories [16]. The Organisation for Economic Cooperation and Development (OECD) performed obesity projections for selected countries up to 2030, assuming that "BMI will continue to rise as a linear function of time" [17]. Other studies, however, took into account the recent evidence indicating that obesity prevalence may actually be leveling off $[18,19]$, and projected a smaller increase up to 2030 [10] or a plateauing in some countries by 2030 .

This study aims to comparatively project obesity prevalence into the long-term future for 18 European countries and the USA using a novel approach.

\section{Materials and Methods}

Please see the online supplementary file I for additional details on the materials and methods (for all online suppl. material, see www.karger.com/doi/10.1159/000511023).

\section{Setting}

We projected future obesity prevalence by age and sex for the national populations aged 20-84 years in the USA and in 18 non-Eastern European countries: Austria, Belgium, Denmark, Finland, France, Germany, Greece, Iceland, Ireland, Italy, Luxembourg, The Netherlands, Norway, Portugal, Spain, Sweden, Switzerland, and the UK.

\section{Data}

Obesity prevalence data (BMI $\geq 30)$ according to age $(20-24, \ldots$, and $85+$ years), sex, country, and year (1975 up to 2016) were obtained from the NCD Risk Factor Collaboration (NCD-RisC) study in 2017 [20]. These data comprise the available measured height and weight data, supplemented with estimates from a Bayesian hierarchical model based on measured height and weight data from other years and related countries.

By applying Loess smoothing, we converted the NCD-RisC obesity prevalence estimates according to 5-year age groups into estimates by single year of age (20-84 years).

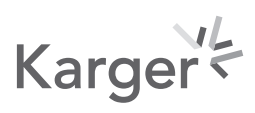


Janssen et al.: Future Obesity Prevalence in Europe and the USA

To enable the comparison of national obesity prevalence estimates over time, we estimated age-standardized obesity prevalence using the country- and sex-specific population age structure in 2010 from the Human Mortality Database [21].

\section{Novel Projection Approach}

We devised a methodology to project obesity prevalence that can generate realistic estimates for both the short- and long-term future. We did so by implementing the notion of a wave-shaped obesity epidemic, which was recently proposed by Xu and Lam [22]. Their model is based on the smoking epidemic model, which illustrates that smoking prevalence increased rapidly and then started declining several decades later, following the successful enactment and implementation of prevention policies in response to the growing social awareness of the negative health effects of smoking [22, 23]. The idea of a wave-shaped evolution of obesity is also in line with the conceptual model of the obesity transition recently proposed by Jaacks et al. [24], which includes a fourth stage in which obesity prevalence is assumed to decline. This assumption is supported by several studies that have reported either a leveling off or stagnation of the increasing obesity trend in the USA [18] and among adults with a high socioeconomic status in Switzerland, France, and Finland [19], or a declining obesity trend among children [25-27].

To integrate the notion of a wave-shaped obesity epidemic into our projection methodology, we utilized the fact that a wave pattern for prevalence is obtained when the logit of prevalence ( $=$ logistically transformed prevalence) has a quadratic shape. To obtain a quadratic shape, we focused on the first-order difference of the time trend in the logit of prevalence, which we refer to as the "speed of change". That is, a quadratic shape is obtained when the speed of change declines linearly over time, from a positive speed (increase), to a zero speed (maximum level), to a negative speed (decline). Thus, by linearly extrapolating the speed of change of the logit of obesity prevalence, we could obtain a wave-shaped pattern based on the data.

For our analysis, we adjusted the Lee and Carter [28] benchmark age-period mortality projection methodology [29], which decomposes logged age-specific mortality into a timeinvariant age pattern, an overall time trend across all ages, and the age-specific magnitude of this time trend; and subsequently extrapolates the overall time trend into the future. We applied the model to logistically transformed age-specific obesity prevalence, and linearly extrapolated the speed of change in the overall time trend of the logit of obesity. We linearly extrapolated the speed of change from the year 2000 onwards, because the decline in the speed of change was steadier during this period than before (see Fig. 2).

Because it is not likely that future obesity prevalence will ever reach zero [22], we implemented country- and sex-specific lower limits in our forecast by making use of the observed obesity prevalence levels in 1975 . These represent the oldest available comparable data.

By performing 100,000 simulations, we obtained projected age-specific and age-standardized obesity prevalence (medians) and their $95 \%$ projection intervals by country and sex up to the year 2100 .

\section{Results}

In the 18 European countries in 2016, the age-standardized (estimated) obesity prevalence (for the age group 20-84 years) ranged from $22.7 \%$ in Portugal to $29.3 \%$ in the UK for men, and from $19.5 \%$ in Switzerland to $31.3 \%$ in the UK for women. The age-standardized obesity prevalence was higher in the USA, at $37.5 \%$ for men and $39.5 \%$ for women (Table 1 , left).

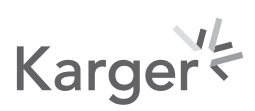


Table 1. Estimated (2016)* and projected (2060) age-standardized obesity prevalence (\%; ages 20-84 years) in the 18 European countries and the USA, by sex

\begin{tabular}{|c|c|c|c|c|}
\hline \multirow[t]{3}{*}{ Country } & \multicolumn{4}{|c|}{ Age-standardized obesity prevalence (\%; ages $20-84$ years) } \\
\hline & \multicolumn{2}{|c|}{ estimated (2016)* } & \multicolumn{2}{|c|}{ projected (2060) and 95\% projection intervals } \\
\hline & men & women & men & women \\
\hline Austria & 24.0 & 21.2 & $25.8(21.8 ; 31.6)$ & $20.6(18.1 ; 24.3)$ \\
\hline Belgium & 25.7 & 24.4 & $27.3(24.0 ; 31.9)$ & $23.2(21.2 ; 26.3)$ \\
\hline Denmark & 24.6 & 19.8 & $29.4(26.2 ; 33.5)$ & $21.1(19.5 ; 23.3)$ \\
\hline Finland & 26.4 & 24.8 & $30.0(25.3 ; 36.5)$ & $24.3(21.5 ; 28.5)$ \\
\hline France & 24.5 & 24.1 & $24.3(21.4 ; 28.4)$ & $21.3(19.7 ; 23.6)$ \\
\hline Germany & 27.2 & 25.3 & $31.0(27.1 ; 36.2)$ & $26.2(23.7 ; 29.6)$ \\
\hline Greece & 26.5 & 29.2 & $33.3(31.1 ; 36.0)$ & $28.2(27.1 ; 29.6)$ \\
\hline Iceland & 26.0 & 21.6 & $27.3(23.3 ; 33.0)$ & $19.6(17.6 ; 22.5)$ \\
\hline Ireland & 27.3 & 28.2 & $26.6(22.6 ; 32.3)$ & $24.3(21.3 ; 28.5)$ \\
\hline Italy & 23.1 & 23.9 & $21.1(18.6 ; 24.6)$ & $21.4(19.8 ; 23.8)$ \\
\hline Luxembourg & 26.8 & 23.2 & $26.1(23.4 ; 29.6)$ & $19.8(18.4 ; 21.7)$ \\
\hline The Netherlands & 23.3 & 23.8 & $13.2(11.8 ; 15.1)$ & $13.3(12.5 ; 14.5)$ \\
\hline Norway & 25.9 & 25.5 & $22.0(18.3 ; 27.8)$ & $19.9(17.6 ; 23.4)$ \\
\hline Portugal & 22.7 & 24.9 & $18.0(15.0 ; 22.4)$ & $17.7(15.8 ; 20.3)$ \\
\hline Spain & 27.5 & 27.2 & $30.0(27.4 ; 33.3)$ & $27.0(25.2 ; 29.3)$ \\
\hline Sweden & 25.0 & 20.8 & $25.3(21.5 ; 30.7)$ & $19.8(17.7 ; 23.0)$ \\
\hline Switzerland & 24.4 & 19.5 & $37.0(33.6 ; 41.2)$ & $26.8(24.4 ; 29.9)$ \\
\hline UK & 29.3 & 31.3 & $24.1(21.6 ; 27.7)$ & $25.7(23.4 ; 28.9)$ \\
\hline USA & 37.5 & 39.5 & $26.9(22.6 ; 33.7)$ & $29.1(25.4 ; 35.1)$ \\
\hline
\end{tabular}

* Source data: NCD-RisC 2017. This data source relies on the available national measured height and weight data, supplemented with estimates from a Bayesian hierarchical model based on information from other years and related countries. We converted the data into data by single year of age (20-84 years), and applied age-standardization using the country- and sex-specific population age structure in 2010.

Between 1975 and 2016, obesity prevalence increased in all the countries studied, although not uniformly (Fig. 1). Especially among women, we observed a recent slowing of the increasing trend in obesity prevalence, particularly in Finland, Greece, and Spain, and, less recently, in Switzerland (Fig. 1).

Overall, the change in the time trend (= speed of change) of the logit of obesity prevalence from 1990 onwards declined for all countries, which indicates that the increasing trend in obesity prevalence was decelerating between 1990 and 2016 (Fig. 2).

In Figure 3, the age-standardized (estimated) obesity prevalence (for the age group 20-84 years) from 1975 to 2016, and the expected obesity prevalence levels and their $95 \%$ projection intervals from 2017 to 2100 , are presented by sex for all countries. The assumed wave pattern of the obesity epidemic is clearly visible.

The USA (44\%), UK (37\%), and Ireland (36\%) are the countries that are expected to reach the highest maximum levels after a deceleration of the increasing trend (Fig. 3; Table 2 ). The lowest maximum levels are expected for men in The Netherlands (28\%) and for women in Denmark (24\%). The year in which the various countries are expected to reach the maximum level ranges from 2030 in The Netherlands to 2052 in Switzerland for men, and from 2026 in The Netherlands to 2054 in Switzerland for women. Next to The Netherlands, the USA (in 2031), Portugal (in 2032), Norway (in 2033), and the UK (in 2033/2034) are also expected to reach their maximum levels relatively early. 

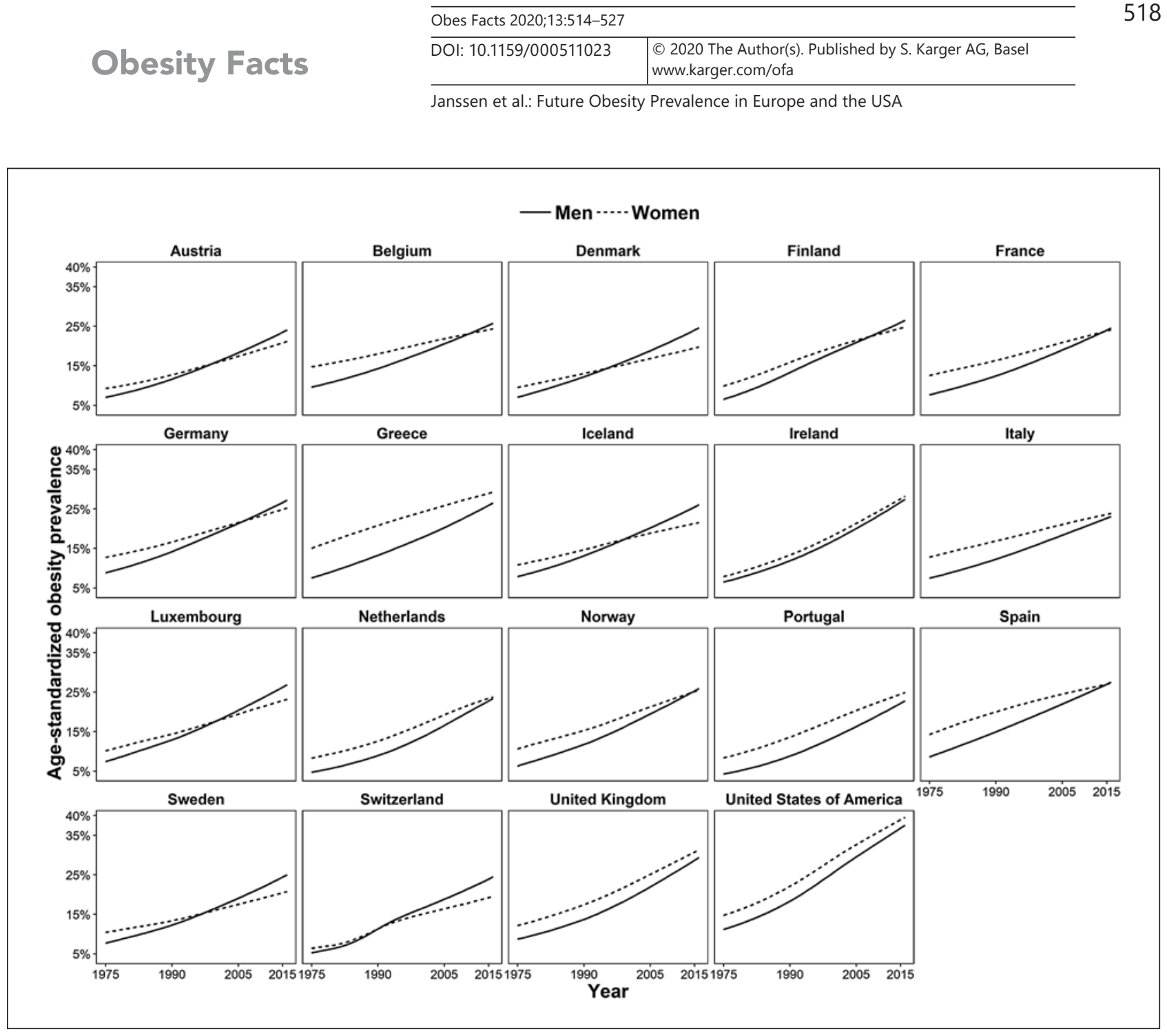

Fig. 1. Age-standardized obesity prevalence (\%; ages 20-84 years) in 18 European countries and the USA in 1975-2016, by sex. For source data, see the footnote to Table 1.

Our projection indicates that after these maximum levels have been reached, obesity will decline at a decelerating pace (Fig. 3). Table 1 (right) summarizes the expected age-standardized obesity prevalence levels, along with the $95 \%$ projection intervals, for the year 2060. Among men, the expected prevalence levels range from $13.2 \%$ (The Netherlands) to $37.0 \%$ (Switzerland). Among women, the expected prevalence levels range from $13.3 \%$ (The Netherlands) to $29.1 \%$ (USA).

Our projected age-specific obesity prevalence levels (online suppl. file II, Fig. S1) display an age pattern similar to the pattern observed in the past, with an inverse U-shape peaking at around the age of 60-69 years.

\section{Discussion}

\section{Summary of Results}

In 2016, the age-standardized (estimated) obesity prevalence (for the age group 20-84 years), based on the NCD-RisC 2017 data, ranged from 29.3\% (UK men) to 19.5\% (Swiss women) in the 18 European countries, compared to about $38.5 \%$ in the USA. In the period 


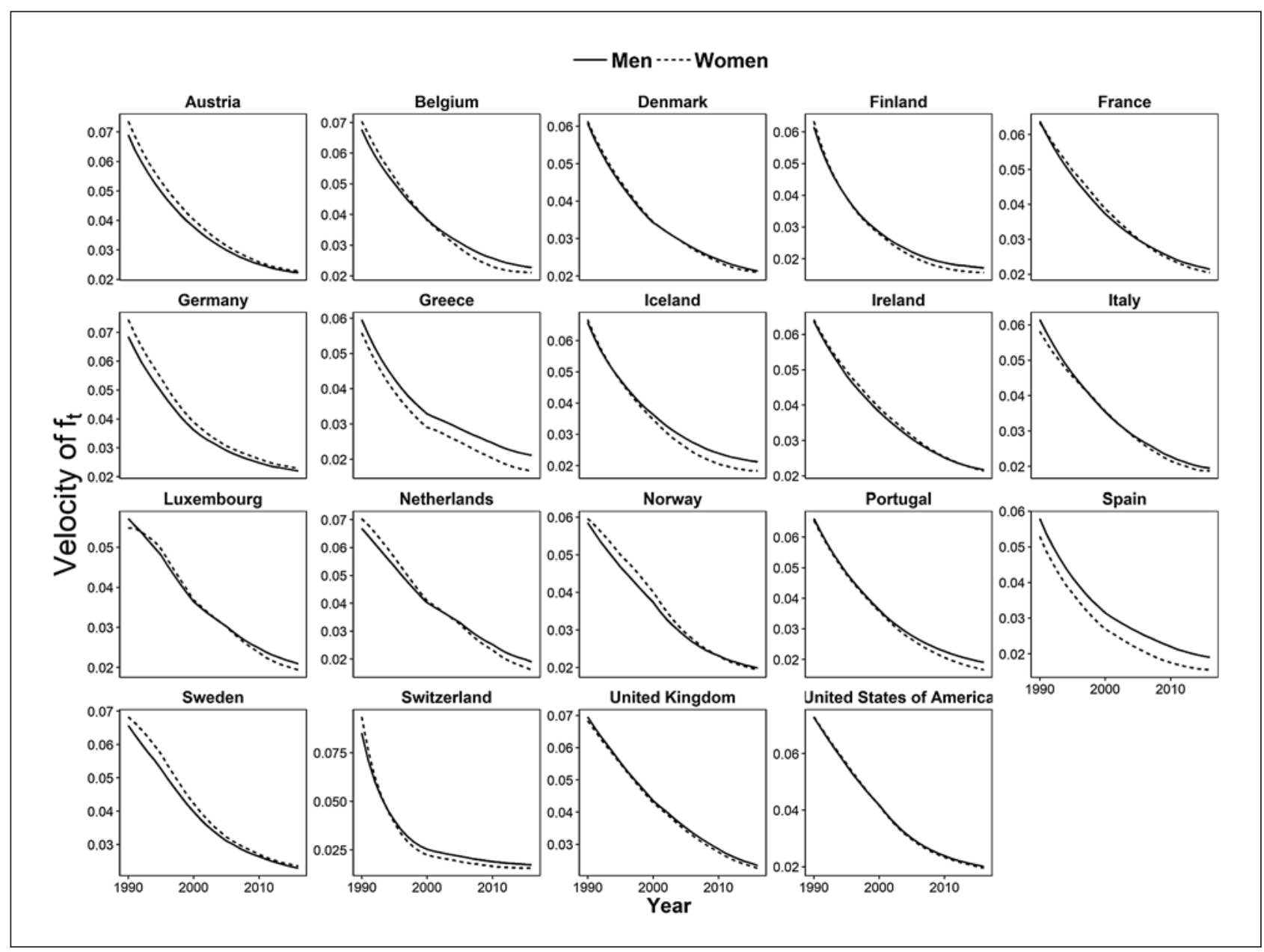

Fig. 2. Speed of change over time (= velocity) of the transformed logit of the obesity prevalence $\mathrm{f}_{t}$ (ages 20 84 years) in 18 European countries and the USA in 1990-2016, by sex. For source data, see the footnote to Table 1.

1990-2016, the increasing trends in age-standardized obesity prevalence were decelerating. By extrapolating the declining speed of change in the obesity prevalence estimates from 2000 onwards, we projected that obesity will reach its maximum levels between 2030 and 2052 among men and between 2026 and 2054 among women. The maximum levels will likely be reached first in The Netherlands, USA, and UK, and last in Switzerland; and are expected to be highest in the USA (44\%) and UK (37\%) and lowest in The Netherlands for men (28\%) and in Denmark for women (24\%). Projections for 2060 indicate that obesity levels will range from $13.2 \%$ (Dutch men) to $37.0 \%$ (Swiss men). As in the past, the projected age-specific obesity prevalence levels have an inverse U-shape, peaking at around the age of 60-69 years.

\section{Discussion of the Results}

A direct comparison of our obesity prevalence projections with previous projections is hampered by the use of different data (e.g., self-reported vs. measured), age groups, and forecasting methodologies (see also "Evaluation of Data and Methodology"). However, most of the previous projections provided short-term forecasts only, and they projected that obesity will increase or, at best, stagnate. Our projections, on the other hand, provide estimates, for the 


\section{Obesity Facts}

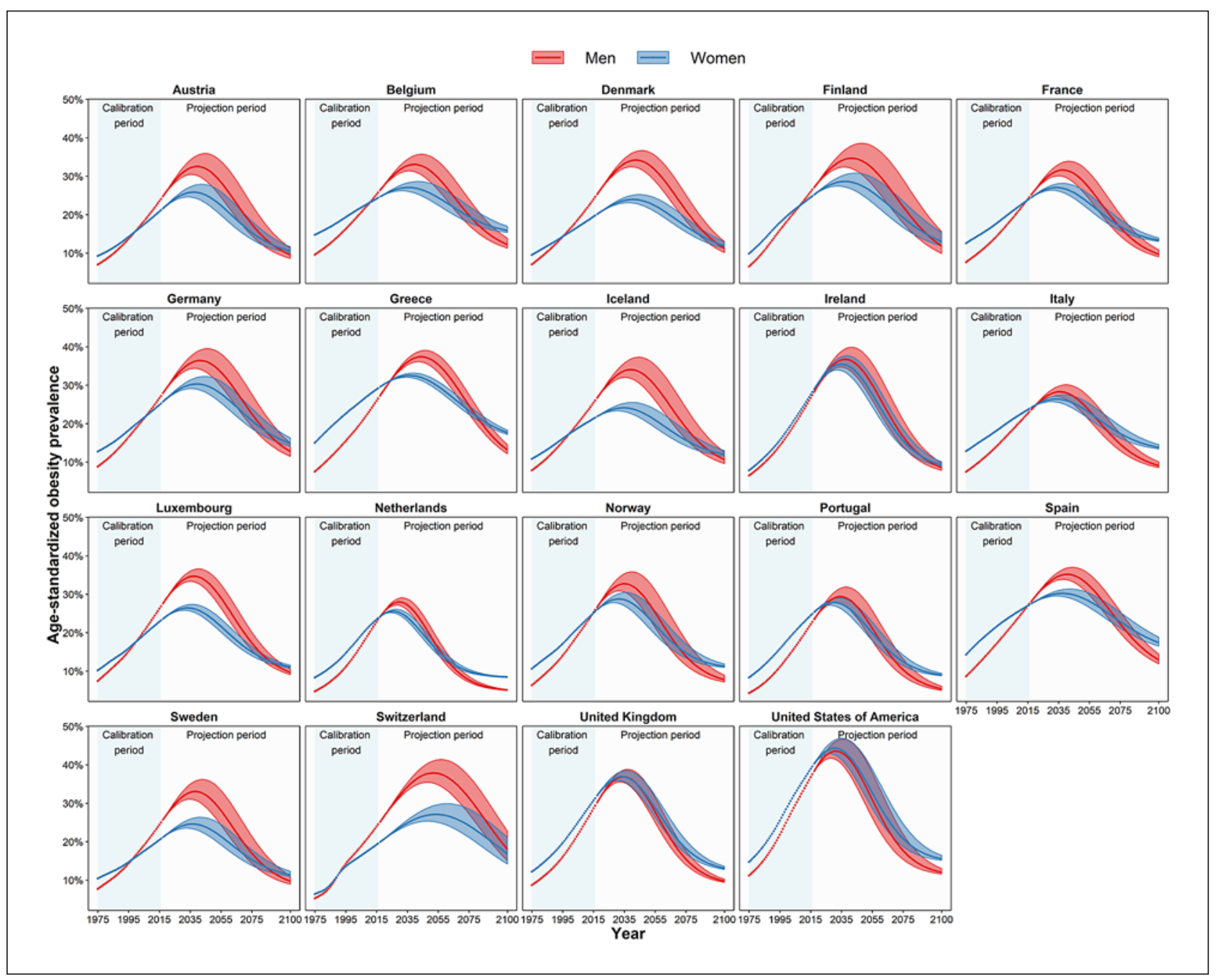

Fig. 3. Estimated* and projected age-standardised obesity prevalence (ages 20-84 years) in 18 European countries and the USA in 1975-2100, by sex. ${ }^{*}$ For source data, see the footnote to Table 1.

long-term, of an initial increase followed by a decline. The previous forecasts that used data comparable to ours, but applied linear extrapolation [6,14], projected considerably higher obesity levels than we have. Wang et al. [6] projected for the USA that, by 2030, 51\% of all adults will be obese. McPherson et al. [14], with the only previous projection for up to 2050 , projected for the UK that, by $2050,50 \%$ of adult women and $60 \%$ of adult men will be clinically obese. Thomas et al. [11], who used a dynamic model that included social and nonsocial influences on weight gain, predicted an obesity prevalence in the USA that remains approximately level from their latest observation (2008) up to 2030, thus predicting obesity estimates for the short-term future that were lower than ours. Finkelstein et al. [10], who used a nonlinear regression model, projected that adult obesity prevalence levels in the USA in 2030 will be $44 \%$, which is almost equal to our projection outcome. However, these previous projections do not provide insights into what is likely going to happen in the long term.

By applying the theoretical model of Xu and Lam [22] to recent national obesity prevalence data for 18 European countries and the USA, we were able to demonstrate that there are important cross-country variations, not only in the increasing trend in obesity prevalence 
Janssen et al:: Future Obesity Prevalence in Europe and the USA

Table 2. Projected maximum levels of age-standardized obesity prevalence (ages 20-84 years) and the year these levels will likely be reached in the 18 European countries and the USA, by sex

\begin{tabular}{|c|c|c|c|c|}
\hline \multirow[t]{2}{*}{ Country } & \multicolumn{2}{|c|}{$\begin{array}{l}\text { Projected maximum obesity prevalence }(\%) \\
\text { and } 95 \% \text { projection intervals }\end{array}$} & \multicolumn{2}{|c|}{$\begin{array}{l}\text { Projected year that the maximum will be } \\
\text { reached and } 95 \% \text { projection intervals }\end{array}$} \\
\hline & men & women & men & women \\
\hline Austria & $32.6(30.5 ; 36.0)$ & $25.9(24.6 ; 27.9)$ & $2040(2035 ; 2045)$ & 2037 (2033; 2043) \\
\hline Belgium & $33.1(31.4 ; 35.7)$ & $27.1(26.2 ; 28.7)$ & $2040(2036 ; 2045)$ & $2036(2031 ; 2043)$ \\
\hline Denmark & $34.2(32.5 ; 36.7)$ & $24.0(23.1 ; 25.2)$ & $2042(2039 ; 2047)$ & $2041(2037 ; 2045)$ \\
\hline Finland & $34.7(32.4 ; 38.6)$ & $28.7(27.4 ; 30.9)$ & $2042(2036 ; 2049)$ & $2037(2032 ; 2045)$ \\
\hline France & $31.6(30.1 ; 33.9)$ & $27.1(26.3 ; 28.2)$ & $2038(2034 ; 2042)$ & $2034(2030 ; 2038)$ \\
\hline Germany & $36.4(34.4 ; 39.6)$ & $30.3(29.1 ; 32.3)$ & $2041(2037 ; 2047)$ & $2039(2035 ; 2045)$ \\
\hline Greece & $37.4(36.1 ; 39.1)$ & $32.5(32.0 ; 33.1)$ & $2044(2042 ; 2047)$ & 2036 (2034; 2039) \\
\hline Iceland & $34.1(32.0 ; 37.3)$ & $24.1(23.3 ; 25.6)$ & $2039(2035 ; 2045)$ & $2034(2030 ; 2041)$ \\
\hline Ireland & $36.8(34.7 ; 39.9)$ & $35.5(34.0 ; 37.7)$ & 2037 (2034; 2042) & 2035 (2032; 2039) \\
\hline Italy & $28.3(27.1 ; 30.1)$ & $26.4(25.7 ; 27.5)$ & $2036(2032 ; 2041)$ & $2034(2030 ; 2039)$ \\
\hline Luxembourg & $34.7(33.3 ; 36.6)$ & $26.4(25.8 ; 27.4)$ & $2037(2035 ; 2041)$ & $2033(2031 ; 2037)$ \\
\hline The Netherlands & $28.0(27.2 ; 29.1)$ & $25.6(25.2 ; 26.1)$ & $2030(2028 ; 2032)$ & $2026(2024 ; 2028)$ \\
\hline Norway & $32.8(30.9 ; 35.9)$ & $28.8(27.8 ; 30.5)$ & $2035(2031 ; 2041)$ & $2031(2028 ; 2037)$ \\
\hline Portugal & $29.4(27.8 ; 31.9)$ & $27.9(27.1 ; 29.1)$ & $2034(2031 ; 2039)$ & $2030(2027 ; 2034)$ \\
\hline Spain & $35.2(33.9 ; 37.0)$ & $30.2(29.5 ; 31.4)$ & $2041(2037 ; 2044)$ & $2037(2033 ; 2043)$ \\
\hline Sweden & $33.1(31.1 ; 36.2)$ & $24.6(23.5 ; 26.4)$ & $2038(2034 ; 2044)$ & $2036(2032 ; 2042)$ \\
\hline Switzerland & $37.9(35.4 ; 41.4)$ & $27.1(25.3 ; 29.9)$ & $2052(2047 ; 2058)$ & $2054(2047 ; 2062)$ \\
\hline UK & $36.9(35.6 ; 38.8)$ & $36.9(35.9 ; 38.5)$ & 2034 (2032; 2038) & $2033(2031 ; 2037)$ \\
\hline USA & $43.6(41.7 ; 46.8)$ & $44.4(42.9 ; 47.0)$ & 2031 (2028; 2037) & $2031(2027 ; 2036)$ \\
\hline
\end{tabular}

but in the expected future levels and regarding the expected timing of the maximum level. Thus, our findings highlight that the severity of the obesity epidemic differs between countries. When we compared our estimates of the timing of the maximum obesity level with the estimates based on the hypothesis of Xu and Lam [22] (which states that a maximum will be reached about 30 years after obesity prevalence is $30 \%$ ), we found that, overall, these estimates were quite similar (online suppl. file II, Table S1). However, for individual populations, important differences could be observed, which suggests that not only the level of obesity prevalence but also the past progression of the obesity epidemic are indicative of the timing of the maximum levels. Also, our expected maximum levels (of up to 44\%, reached in the USA) are quite distant from the theoretical worldwide maximum obesity level of $60 \%$ that Xu and Lam [22] postulated. Thus, our results clearly suggest that the outcomes of a general theoretical model designed for application worldwide differ from those of an application of the theory to data for a subset of countries.

We project that the USA and UK will reach the highest maximum levels and will reach these relatively early. This outcome is in line with their current forerunner positions, the previous literature, and a previous forecast that focused on few European countries and the USA [8]. The UK is regarded as the forerunner in obesity in Europe, not only because it has high levels of obesity, but because the increase in obesity prevalence has been greater than increases elsewhere in Europe [20,30-34] and are similar to trends observed in the USA [32, $34,35]$. In addition to having similar obesity levels and progression histories [1, 34, 35], the UK and USA share certain characteristics that might predispose their populations to having similar eating and physical activity habits (e.g., there is widespread consumption of fast food, levels of socioeconomic inequality are high, and obese people are stigmatized) $[35,36]$. However, the UK is expected to reach lower maximum levels and a couple of years later than the USA, possibly due to differences in socioeconomic conditions, food policies, and access to

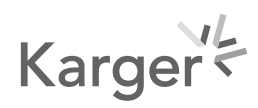


Janssen et al.: Future Obesity Prevalence in Europe and the USA

food technology in these 2 countries [32, 35]. All in all, however, the trends in the UK are following those in the USA rather closely, while the trends in the other European countries, led by Ireland, are following those in the UK.

Variations in timing and levels of obesity prevalence that we project for the remaining European countries can largely be explained by their current obesity prevalence rankings. The current differences between countries reflect differences in the onset and progression of the obesity epidemic, which are related to differences in cultural, socioeconomic, nutritional, and environmental conditions $[20,36]$.

Our projection shows that, for many countries, the obesity level rankings in 2016 are approximately the same as their projected (maximum) obesity level rankings. For example, Ireland, Greece, and Spain (and the USA and UK) are projected to maintain their relatively high obesity prevalence levels; Iceland, Belgium, and Finland are projected to maintain their intermediate levels; and Sweden is projected to maintain its relatively low obesity prevalence level. These outcomes are in line with our expectations as well as with a recent study projecting obesity up to the year 2025 in European countries [12].

However, the projected obesity level rankings and the currently observed obesity level rankings were not aligned in all the countries studied. In particular, Switzerland and Denmark, which have low-to-intermediate rankings, based on the latest available obesity data, are projected to have intermediate-to-high rankings in the future. On the other hand, The Netherlands and Portugal, which currently have low-to-intermediate rankings, are projected to have very low rankings in the future, mainly due to favorable trends among women. Moreover, Norway is projected to go from having an above-average obesity prevalence level to a belowaverage level. These projected changes in country rankings can be explained by the crosscountry differences in the deceleration in obesity increases after the year 2000 (Fig. 2).

\section{Evaluation of the Data and Our Methodology}

Any projection outcome depends on the data, model, and underlying assumptions used. For the data, we selected the longest available time series (1975-2016) of age- and sexspecific obesity prevalence data that are comparable over time and between populations, in order to arrive at reliable and comparable extrapolations. The data we used from the NCD-RisC 2017 study relied on meticulous collection and pooling of the available population-level based information by country on measured height and weight. A Bayesian hierarchical model was used to generate estimates for each country and year based on the available data, and data from other years and related countries [20]. Their model has been validated [30], and the WHO adopted the estimates generated as part of their Global Health Observatory Data Repository [37].

It is important to mention that the NCD-RisC obesity prevalence estimates, relying on measured height and weight data, are generally substantially higher than national obesity prevalence estimates that rely on self-reported height and weight. Our online supplementary file III, which provides a comparison of obesity prevalence estimates from different data sources, also illustrates this point. Because people with a high BMI tend to underreport their body weight, self-reported BMI data can indeed be substantially biased downwards [38-40]. Moreover, because this bias varies over time, obesity prevalence trends based on self-reported height and weight data tend to be biased $[38,41]$.

Although the NCD-RisC 2017 obesity data avoid this bias, the data are primarily estimates based on the available national measured height and weight data which are often incomplete, and thus uncertain. Table 1 of the online supplementary file III shows that levels of uncertainty are highest in Austria, Luxembourg, Portugal, France, and Switzerland; and lowest in the UK and USA. Furthermore, it should be noted that our projected levels of obesity prevalence relate to the smoothed NCD-RisC 2017 obesity prevalence estimates for the age group

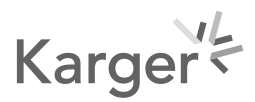


Janssen et al.: Future Obesity Prevalence in Europe and the USA

Table 3. Projected annual absolute changes in age-standardized obesity prevalence (\%; ages 20-84 years) in 18 European countries and the USA, by sex, from 2016 until the year that the maximum is projected to be reached (peak year), and from the peak year to 2060

\begin{tabular}{|c|c|c|c|c|c|c|}
\hline \multirow[t]{2}{*}{ Country } & \multicolumn{2}{|c|}{$\begin{array}{l}\text { Year that the maximum is } \\
\text { projected to be reached } \\
\text { (peak year) }\end{array}$} & \multicolumn{2}{|c|}{$\begin{array}{l}\text { Projected annual change in obesity } \\
\text { prevalence from } 2016 \text { to peak year } \\
\text { (in percentage points) }\end{array}$} & \multicolumn{2}{|c|}{$\begin{array}{l}\text { Projected annual change in obesity } \\
\text { prevalence from peak year to } 2060 \\
\text { (in percentage points) }\end{array}$} \\
\hline & men & women & men & women & men & women \\
\hline Austria & 2040 & 2037 & 0.36 & 0.22 & -0.34 & -0.23 \\
\hline Belgium & 2040 & 2036 & 0.31 & 0.14 & -0.29 & -0.16 \\
\hline Denmark & 2042 & 2041 & 0.37 & 0.17 & -0.27 & -0.15 \\
\hline Finland & 2042 & 2037 & 0.32 & 0.18 & -0.26 & -0.19 \\
\hline France & 2038 & 2034 & 0.32 & 0.16 & -0.33 & -0.22 \\
\hline Germany & 2041 & 2039 & 0.37 & 0.22 & -0.29 & -0.20 \\
\hline Greece & 2044 & 2036 & 0.39 & 0.17 & -0.26 & -0.18 \\
\hline Iceland & 2039 & 2034 & 0.35 & 0.14 & -0.32 & -0.18 \\
\hline Ireland & 2037 & 2035 & 0.45 & 0.38 & -0.44 & -0.45 \\
\hline Italy & 2036 & 2034 & 0.26 & 0.14 & -0.30 & -0.19 \\
\hline Luxembourg & 2037 & 2033 & 0.38 & 0.19 & -0.38 & -0.25 \\
\hline The Netherlands & 2030 & 2026 & 0.33 & 0.18 & -0.49 & -0.36 \\
\hline Norway & 2035 & 2031 & 0.36 & 0.22 & -0.43 & -0.31 \\
\hline Portugal & 2034 & 2030 & 0.37 & 0.21 & -0.44 & -0.34 \\
\hline Spain & 2041 & 2037 & 0.31 & 0.14 & -0.27 & -0.14 \\
\hline Sweden & 2038 & 2036 & 0.37 & 0.19 & -0.35 & -0.20 \\
\hline Switzerland & 2052 & 2054 & 0.37 & 0.20 & -0.11 & -0.05 \\
\hline UK & 2034 & 2033 & 0.42 & 0.33 & -0.49 & -0.42 \\
\hline USA & 2031 & 2031 & 0.41 & 0.32 & -0.58 & -0.53 \\
\hline
\end{tabular}

20-84 years, which we age-standardized using the country- and sex-specific population age structure in 2010. Because trends over time based on the NCD-RisC data, and based on our slight adjustments of these data seem to resemble the trends in the national measured height and weight data from the OECD database (online suppl. file III, Fig. I), our projected maximum year of obesity prevalence and the projected annual absolute increases and subsequent declines (Table 3) can be applied to the available national obesity prevalence data based on measured height and weight.

In terms of the methodology, we applied a novel approach to enable the projection of obesity into the long-term future. Most previous obesity projections considered the shortterm future only [6-14] and used methodologies not designed to generate reliable long-term estimates. For example, linear extrapolations of past trends in obesity prevalence $[6,14-17]$ tend to generate unrealistically high obesity prevalence levels for the long-term future. Instead of extrapolating past trends in obesity prevalence, we extrapolated changes in these trends (first-order differences), and consequently projected declines in obesity prevalence in the long term. These projected long-term declines are in line with the wave-shaped obesity epidemic model proposed by Xu and Lam [22], the fourth stage of the conceptual model of the obesity transition proposed by Jaacks et al. [24], and the decline in obesity prevalence among children observed in many developed countries [25-27].

However, the assumption that obesity is an epidemic with an underlying wave pattern has been debated [19] and is not set in stone. For example, some scholars have argued that previous studies reporting decelerating increases have misinterpreted the data due to bias, and that any stagnation is temporary and will be followed by further increases [19]. But evidence showing that obesity has been declining among children in many developed coun- 
tries [25-27] bolsters the claim that obesity is a wave-shaped epidemic, as these cohorts of leaner children will likely grow into leaner adults [24]. Moreover, our finding that the increases in obesity between 1990 and 2016 were decelerating for all countries under study is an important observation that is in line with the wave-shaped epidemic model. However, to ensure that this decelerating trend leads to a leveling off, followed by a decline in obesity in the long run, effective, ongoing public health action aimed at tackling obesity is required.

We applied one model for the sex-specific populations of 18 European countries and the USA to obtain obesity estimates for the long-term future that can be readily compared between the different countries. So far, the comparison of obesity projection outcomes was hampered by the use of different data, methodologies, and underlying assumptions. For the projection of obesity prevalence in individual countries, however, it may be beneficial to include countryspecific information on the determinants of (trends in) obesity prevalence in the model.

We modeled and projected obesity prevalence using age-period modeling and projecting. This often-used approach accounts for age-specific differences in obesity prevalence and differences over (calendar) time. However, it does not capture differences in obesity prevalence between birth cohorts or generations, even though recent studies have clearly demonstrated the importance of including the cohort dimension (next to age and period) in analyses of obesity prevalence trends [42-44] and obesity-attributable mortality [33]. We decided to apply age-period modeling mainly because the application of age-period-cohort modeling to the data resulted in unrealistically similar cohort patterns for the different countries. This problem likely arose because the data were estimated using a model that included only the age and period dimensions [20]. We recommend that future obesity projections include the cohort dimension in obesity projections. For our projection approach, this would mean extending the underlying model and appropriately projecting the population-specific cohort parameters.

As in any projection or extrapolation of past trends, our projection outcomes were dependent on the underlying data used and the explicit choices made [45]. For example, choosing a different start year (instead of 2000) for the extrapolation of the speed of change would result in different levels and years at which the maximum will be reached (online suppl. file II, Tables S2 and S3). However, the overall conclusions would be unchanged. The assumed lower limits could also affect our projection outcomes. In choosing these limits, we optimally used both the available theory and available data, accounting for country and sex differences in the importance of the obesity epidemic. Our assumed lower limits proved, on average, to be very close to the $10 \%$ level that Xu and Lam [22] expected obesity to reach at the final stage of the epidemic (online suppl. file II, Fig. S2). Our sensitivity analysis revealed that the assumed level of the lower limits has a large effect over the long run, but a smaller effect on the expected maximum level of obesity and its timing (online suppl. file I). Still, our projection outcomes need to be interpreted with the assumed lower limits in mind. In fact, the assumed lower limit can be regarded a model parameter which can be adjusted, e.g., to assess the likely influence of an important change in public health policy.

\section{Conclusions}

Applying our novel approach to project obesity prevalence into the long-term future to the NCD-RisC 2017 data, we estimated that the obesity epidemic will, on average over the 18 European countries studied, reach its peak in 2037 at an average age-standardized obesity prevalence level of 31\% for the age group of 20-84 years. Although dependent on the underlying data and assumptions, this projected level represents a considerable increase from the estimated average level of $25 \%$ in 2016 . Furthermore, we also estimated large cross-country

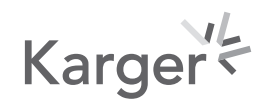


differences in future obesity prevalence that are mostly (although not completely) in line with the current obesity prevalence rankings. The USA and UK are expected to maintain their forerunner positions in the obesity epidemic.

In our approach, we implemented the notion of a wave-shaped obesity epidemic, in line with the model recently proposed by Xu and Lam [22], the conceptual model proposed by Jaacks et al. [24], recent literature indicating obesity declines among children, and our observation that the increasing obesity trend has been decelerating for all studied populations between 1990 and 2016. To ensure that this slowdown in the increasing trend in obesity continues and turns into the projected declines in the long run, effective, ongoing public health action aimed at tackling obesity is required. For countries with continuously high obesity prevalence (e.g., the USA, UK, Ireland, Greece, and Spain) and those expected to lose their favorable position (e.g., Switzerland and Denmark), we recommend special attention.

\section{Statement of Ethics}

Ethics approval was not required as the research makes use of aggregate secondary data which is publicly available and from which individuals cannot be identified.

\section{Conflict of Interest Statement}

The funding source had no role in the study design, collection, analysis, or interpretation of the data; writing the manuscript; or the decision to submit the paper for publication. F.J. and N.V. declare no financial relationships with any organisations that might have had an interest in the submitted work in the last 3 years. A.B. reports personal fees from Nationale Nederlanden, which he received outside the submitted work, and only after his work on the paper was completed.

\section{Funding Sources}

This work is funded by The Netherlands Organisation for Scientific Research (NWO) under grant No. 452-13-001.

\section{Author Contributions}

F.J. conceived the study. All authors designed the study. F.J. and N.V. performed the literature search. N.V. obtained the data and performed initial analyses. A.B. developed the projection model and performed the projections, with input from F.J. and N.V. All authors interpreted the results. A.B. made the final figures with input from F.J. and N.V. N.V. and F.J. drafted the manuscript. F.J. revised the manuscript. All authors approved the final version of the manuscript.

\section{Karger'k}




\begin{tabular}{|c|c|}
\hline Obes Facts 2020;13:514-527 & \\
\hline DOI: 10.1159/000511023 & $\begin{array}{l}\text { (c) } 2020 \text { The Author(s). Published by S. Karger AG, Basel } \\
\text { www.karger.com/ofa }\end{array}$ \\
\hline
\end{tabular}

Janssen et al.: Future Obesity Prevalence in Europe and the USA

\section{References}

1 Finucane MM, Stevens GA, Cowan MJ, Danaei G, Lin JK, Paciorek CJ, et al.; Global Burden of Metabolic Risk Factors of Chronic Diseases Collaborating Group (Body Mass Index). National, regional, and global trends in body-mass index since 1980: systematic analysis of health examination surveys and epidemiological studies with 960 country-years and 9·1 million participants. Lancet. 2011 Feb;377(9765):557-67.

2 WHO. Obesity. 2018; Available at: http://www.euro.who.int/en/health-topics/noncommunicable-diseases/ obesity/obesity.

3 OECD. Obesity and the economics of prevention: fit not fat. Key facts - United States, update 2014. Paris: OECD Publishing; 2014.

4 Eurostat. European Health Interview Survey - Almost 1 adult in 6 in the EU is considered obese - Share of obesity increases with age and decreases with education level. Eurostat news release 20 October 2016.

5 WHO. Obesity: preventing and managing the global epidemic. Report of a WHO consultation. WHO Technical Report Series 894. Geneva: World Health Organization; 2000.

6 Wang Y, Beydoun MA, Liang L, Caballero B, Kumanyika SK. Will all Americans become overweight or obese? Estimating the progression and cost of the US obesity epidemic. Obesity (Silver Spring). 2008 Oct;16(10): 2323-30.

7 Sassi F, Devaux M, Cecchini M, Rusticelli E. The obesity epidemic: analysis of past and projected future trends in selected OECD countries. OECD Health Working Papers 45. Paris: OECD Publishing; 2009.

8 Schneider H, Dietrich ES, Venetz WP. Trends and stabilization up to 2022 in overweight and obesity in Switzerland, comparison to France, UK, US and Australia. Int J Environ Res Public Health. 2010 Feb;7(2):460-72.

9 Wang YC, McPherson K, Marsh T, Gortmaker SL, Brown M. Health and economic burden of the projected obesity trends in the USA and the UK. Lancet. 2011 Aug;378(9793):815-25.

10 Finkelstein EA, Khavjou OA, Thompson H, Trogdon JG, Pan L, Sherry B, et al. Obesity and severe obesity forecasts through 2030. Am J Prev Med. 2012 Jun;42(6):563-70.

11 Thomas DM, Weedermann M, Fuemmeler BF, Martin CK, Dhurandhar NV, Bredlau C, et al. Dynamic model predicting overweight, obesity, and extreme obesity prevalence trends. Obesity (Silver Spring). 2014 Feb; 22(2):590-7.

12 Pineda E, Sanchez-Romero LM, Brown M, Jaccard A, Jewell J, Galea G, et al. Forecasting Future Trends in Obesity across Europe: The Value of Improving Surveillance. Obes Facts. 2018;11(5):360-71.

13 Keaver L, Webber L, Dee A, Shiely F, Marsh T, Balanda K, et al. Application of the UK foresight obesity model in Ireland: the health and economic consequences of projected obesity trends in Ireland. PLoS One. 2013 Nov; 8(11):e79827.

14 McPherson K, Marsh T, Brown M. Tackling obesities: future choices - modelling future trends in obesity and the impact on health. UK: Government Office for Science (Foresight); 2007.

15 Kelly T, Yang W, Chen CS, Reynolds K, He J. Global burden of obesity in 2005 and projections to 2030. Int J Obes. 2008 Sep;32(9):1431-7.

16 Foreman KJ, Marquez N, Dolgert A, Fukutaki K, Fullman N, McGaughey M, et al. Forecasting life expectancy, years of life lost, and all-cause and cause-specific mortality for 250 causes of death: reference and alternative scenarios for 2016-40 for 195 countries and territories. Lancet. 2018 Nov;392(10159):2052-90.

17 OECD. Obesity update 2017. Paris: OECD Publishing; 2017.

18 Rokholm B, Baker JL, Sørensen TI. The levelling off of the obesity epidemic since the year 1999—a review of evidence and perspectives. Obes Rev. 2010 Dec;11(12):835-46.

19 Visscher TL, Heitmann BL, Rissanen A, Lahti-Koski M, Lissner L. A break in the obesity epidemic? Explained by biases or misinterpretation of the data? Int J Obes. 2015 Feb;39(2):189-98.

20 Abarca-Gómez L, Abdeen ZA, Hamid ZA, Abu-Rmeileh NM, Acosta-Cazares B, Acuin C, et al.; NCD Risk Factor Collaboration (NCD-RisC). Worldwide trends in body-mass index, underweight, overweight, and obesity from 1975 to 2016: a pooled analysis of 2416 population-based measurement studies in 128.9 million children, adolescents, and adults. Lancet. 2017 Dec;390(10113):2627-42.

21 Human Mortality Database. University of California, Berkeley (USA), and Max Planck Institute for Demographic Research (Germany). 2018; Available from: http://www.mortality.org. Accessed Sept 1, 2018.

22 Xu L, Lam TH. Stage of obesity epidemic model: learning from tobacco control and advocacy for a framework convention on obesity control. J Diabetes. 2018 Jul;10(7):564-71.

23 Lopez AD, Collishaw NE, Piha T. A Descriptive Model of the Cigarette Epidemic in Developed Countries. Tob Control. 1994;3(3):242-7.

24 Jaacks LM, Vandevijvere S, Pan A, McGowan CJ, Wallace C, Imamura F, et al. The obesity transition: stages of the global epidemic. Lancet Diabetes Endocrinol. 2019 Mar; 7(3):231-40.

25 Wabitsch M, Moss A, Kromeyer-Hauschild K. Unexpected plateauing of childhood obesity rates in developed countries. BMC Med. 2014 Jan;12(17):17.

26 Pan L, Freedman DS, Park S, Galuska DA, Potter A, Blanck HM. Changes in Obesity Among US Children Aged 2 Through 4 Years Enrolled in WIC During 2010-2016. JAMA. 2019 Jun;321(23):2364-6.

27 Lauria L, Spinelli A, Buoncristiano M, Nardone P. Decline of childhood overweight and obesity in Italy from 2008 to 2016: results from 5 rounds of the population-based surveillance system. BMC Public Health. 2019 May;19(1):618.

28 Lee RD, Carter LR. Modeling and forecasting US mortality. JASA. 1992;87(419):659-71.

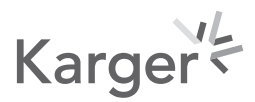


29 Janssen F. Advances in mortality forecasting: introduction. Genus. 2018;74(21):1-12.

30 NCD Risk Factor Collaboration (NCD-RisC). Trends in adult body-mass index in 200 countries from 1975 to 2014: a pooled analysis of 1698 population-based measurement studies with 19.2 million participants. Lancet. 2016 Apr;387(10026):1377-96.

31 Lifestyles statistics team, Health and Social Care Information Centre. Statistics on Obesity, Physical Activity and Diet: England 2014. 2014; Government UK: Health and Social Care Information Centre; 2014.

32 Cutler DM, Glaeser EL, Shapiro JM. Why Have Americans Become More Obese? J Econ Perspect. 2003;17(3): 93-118.

33 Vidra N, Bijlsma MJ, Trias-Llimós S, Janssen F. Past trends in obesity-attributable mortality in eight European countries: an application of age-period-cohort analysis. Int J Public Health. 2018 Jul;63(6):683-92.

34 Vidra N, Trias-Llimós S, Janssen F. Impact of obesity on life expectancy among different European countries: secondary analysis of population-level data over the 1975-2012 period. BMJ Open. 2019 Jul;9(7):e028086.

35 Donahue J. Obesity in the US and UK. J Nutr Food Sci. 2018;8(4):1-5.

36 Blundell JE, Baker JL, Boyland E, Blaak E, Charzewska J, de Henauw S, et al. Variations in the Prevalence of Obesity Among European Countries, and a Consideration of Possible Causes. Obes Facts. 2017;10(1):25-37.

37 WHO. Prevalence of obesity among adults. 2017; Available from: https://apps.who.int/gho/data/node.main. BMI30C?lang=en, and https://apps.who.int/gho/data/node.main.A900A?lang=en. Accessed Sept 21, 2019.

38 Ezzati M, Martin H, Skjold S, Vander Hoorn S, Murray CJ. Trends in national and state-level obesity in the USA after correction for self-report bias: analysis of health surveys. J R Soc Med. 2006 May; 99(5):250-7.

39 Connor Gorber S, Tremblay M, Moher D, Gorber B. A comparison of direct vs. self-report measures for assessing height, weight and body mass index: a systematic review. Obes Rev. 2007 Jul;8(4):307-26.

40 Tolonen H, Koponen P, Mindell JS, Männistö S, Giampaoli S, Dias CM, et al.; European Health Examination Survey Pilot Project. Under-estimation of obesity, hypertension and high cholesterol by self-reported data: comparison of self-reported information and objective measures from health examination surveys. Eur J Public Health. 2014 Dec;24(6):941-8.

41 Hayes AJ, Clarke PM, Lung TW. Change in bias in self-reported body mass index in Australia between 1995 and 2008 and the evaluation of correction equations. Popul Health Metr. 2011 Sep 25; 9:53.

42 Faeh D, Bopp M. Increase in the prevalence of obesity in Switzerland 1982-2007: birth cohort analysis puts recent slowdown into perspective. Obesity (Silver Spring). 2010 Mar;18(3):644-6.

43 Robinson WR, Keyes KM, Utz RL, Martin CL, Yang Y. Birth cohort effects among US-born adults born in the 1980s: foreshadowing future trends in US obesity prevalence. Int J Obes. 2013 Mar;37(3):448-54.

44 Diouf I, Charles MA, Ducimetière P, Basdevant A, Eschwege E, Heude B. Evolution of obesity prevalence in France: an age-period-cohort analysis. Epidemiology. 2010 May;21(3):360-5.

45 Stoeldraijer L, van Duin C, van Wissen L, Janssen F. Impact of different mortality forecasting methods and explicit assumptions on projected future life expectancy: the case of the Netherlands. Demogr Res. 2013; 29(13):323-54. 